\title{
Tax-tariff reform with costs of tax administration ${ }^{*}$
}

\author{
Knud J. Munk ${ }^{\dagger}$ \\ University of Aarhus
}

First Version: August 2004

This Version: May 2006

\begin{abstract}
As is broadly recognized, the straightforward application of the DiamondMirrlees (1971) production efficiency theorem implies that when lump-sum taxation is not available, then it is optimal for the government in a small open economy to rely on taxes on the net demand of households rather than on border taxes to finance its resource requirements. However, the theorem does not hold when taxation is associated with administrative costs. The present paper explores the implications for optimal taxation and for desirable directions of tax-tariff reform in countries at different levels of economic development, taking into account the costs of tax administration. The paper clarifies the reasons for, and lends support to, the criticism by Emran and Stiglitz (2005) of the IMF and the World Bank's recommendation to developing countries to adopt VAT to replace border taxes.
\end{abstract}

Keywords: Optimal taxation, optimal trade policy, VAT, tax-tariff reform, costs of tax administration, informal sector, developing countries

JEL classification codes: F11, F13, H21

Accepted for publication in International Tax and Public Finance

\begin{abstract}
* Previous versions of this paper have been presented at the International Conference on Public Sector Transition organised by the Association for Studies in Public Economics, St Petersburg, November 2003; at the ECOMOD conference in Paris, July 2004; the IIPF Conference in Milan, August 2004; the Danish International Economics Workshop in Aarhus, March 2005; and at the MENA Conference in Brussels, June 2005. Comments from the participants in these events, in particular from John Wilson, are gratefully acknowledged. I also want to thank David Bevan, Richard Bird, Christopher Heady, Carsten Kowalczyk, Pascalis Raimondos-Møller, and two anonymous referees for helpful comments and suggestions.
\end{abstract}

${ }^{\dagger}$ Department of Economics, University of Aarhus, Building 1322, DK 8000 Aarhus C. E-mail: kmunk@econ.au.dk 


\section{Introduction}

In a seminal paper, Diamond and Mirrlees (1971) established that even when lump-sum taxation is not available, production efficiency is desirable. However, as Stiglitz and Dasgupta (1971) pointed out at the outset, the Diamond-Mirrlees efficiency theorem is not very robust considering that production efficiency will not necessarily be desirable if certain tax instruments cannot be used.

Under the assumption that all market transactions and profit can be taxed, the conditions for a taxtariff system to be optimal are fairly well understood. It is a corollary to the Diamond-Mirrlees (1971) production efficiency theorem that, in a small open economy, it is optimal for the government to rely on taxes on the net demand of households, rather than to use border taxes (see Dixit and Norman 1980, Dixit 1985). On the other hand, it also follows from Stiglitz and Dasgupta's analysis that free trade is in general not desirable if all tax instruments cannot be set costlessly at their optimal level. This latter implication was explored by Dasgupta and Stiglitz (1974) and by Heady and Mitra (1982, 1987). That tax restrictions, as in Stiglitz and Dasgupta (1971) and Munk (1980), are exogenously given, is an unattractive assumption which already in 1982 made Heady and Mitra identify the development of a theory of costly administration, which would permit an endogenous choice of tax restrictions, as a priority for future research. However, although the importance of administrative costs has been widely recognised, little progress has been made to incorporate administrative costs into the theory of optimal taxation.

There is a considerable literature on desirable directions of tariff reform. Hatta (1977) analysed the welfare effects of tariff reform when changes in government tax revenue are balanced by changes in lump-sum transfers. Subsequent contributions (see for example Diewert, Turunen-Red, and Woodland 1989) took into account that the revenue forgone by tariff reductions has to be replaced by tax revenue generated by other distortionary taxes. However, in general, this work has been done within a framework where free trade would be the ultimate aim of such reform. As Keen and Ligthart (2002) have pointed out, this literature is thus of limited relevance for identifying desirable directions of tax-tariff reforms when the set of feasible tax instruments is restricted and free trade therefore in general not desirable. In the same vein, Emran and Stiglitz (2005) have argued that traditional theory - with its implication that free trade is always desirable - cannot be used as the basis for providing policy advice on tax-tariff reform in developing and transition countries. In particular, they have criticised the IMF and the World Bank recommendation to reduce trade taxes and increase consumption taxes, such as VAT, as likely to decrease rather than increase welfare in developing countries with large informal sectors.

The present paper addresses the challenge of developing a theory of optimal taxation which permits an endogenous choice of tax restrictions. A critical element in this endeavour is the formulation of assumptions that associate different tax structures with different administrative costs. The analysis thereby provides a framework for gaining insight into how the optimal tax-tariff system in the course of economic development changes in response to reductions in the relative costs of tax administration. ${ }^{1}$ This, in turn, provides the basis for evaluating tax-tariff reform in general and, more specifically, the above mentioned criticism by Emran and Stiglitz (2005). They emphasise the importance of administrative costs, but employ a model without the representation of these costs.

\footnotetext{
1 The paper thus responds to the challenge to develop optimal tax theory to be of greater relevance for developing countries, addressed to the profession by Joe Stiglitz at the IIPF conference in Prague 2003.
} 
The present analysis may thus be seen as an articulation of the assumptions on which their analysis is implicitly based.

The paper is structured as follows. Section 2 briefly reviews the empirical evidence on costs of tax administration and specifies simplifying assumptions for the subsequent analysis. In Section 3, the government's maximisation problem is formulated taking administrative costs into account, and in Section 4, the optimal tax systems is derived and characterised for four different tax structures. On this basis, in Section 5, desirable directions of coordinated tax-tariff reforms in response to improvement in administrative infrastructure are identified, and the policy implications discussed. Section 6 summarises and concludes.

\section{Administrative costs of tax administration}

Empirical research on the existence and impact of the operating costs of taxation has flourished in recent years. Although still lacking in a number of respects this research makes it possible to draw some definite conclusions. Evans (2003) reports, based on a review of a large number of studies, government costs of tax collection and enforcement in the order of $1 \%$, and private costs of tax compliance of $3-10 \%$ of the tax revenue. Furthermore, he finds that taxing domestic transactions in general is more costly than taxing foreign transactions. The OECD (2004) has undertaken a major study of the costs of tax administration in the OECD countries which also suggests that tax administration is associated with significant costs. Bird (2005) has reviewed the lessons from the experience with VAT in transition and developing countries. Overall, he finds that there is surprisingly little solid empirical knowledge of some critical factors, and that the relevant economic theory remains sketchy ${ }^{2}$, but based on case studies he identifies a number of particular problems facing developing countries with respect to VAT design and administration which suggest that the cost of tax administration are of relative greater importance in developing than in developed countries. This is consistent with conclusions reached in a previous study by World Bank (1988).

In order to incorporate the insights from the empirical studies into the theory of optimal taxation, we employ the following conceptual framework: a tax-tariff system, $\boldsymbol{\tau}$, is defined as the values of all tax instruments, and a tax-tariff structure $j, \boldsymbol{\Xi}^{j}=\boldsymbol{\Xi}(\boldsymbol{\tau})$, as the set of tax-tariff systems, $\boldsymbol{\tau} \in \boldsymbol{\Xi}^{j}$, where the same restrictions are imposed on the set of tax instruments. Governments are assumed to consider four different tax structures:

$$
\begin{aligned}
& \Xi^{1}: \text { no tax-tariff restrictions; } \\
& \Xi^{2} \text { : only a primary factor tax and border taxes are feasible; } \\
& \Xi^{3} \text { : only border taxes are feasible; and } \\
& \Xi^{4} \text { : only border taxes at a uniform rate are feasible. }
\end{aligned}
$$

Using this conceptual framework, we make the following simplifying assumptions:

\footnotetext{
${ }^{2}$ Bird quotes Laffont (2004) for making similar observations with respect to public utility regulation in developing and transition countries.
} 
A1: The costs of tax administration associated with a given tax-tariff system, $\boldsymbol{\tau}$, at a given level of economic development $d$, are equal to $B(\boldsymbol{\Xi}, d)$, where $\boldsymbol{\Xi}=\mathbf{\Xi}(\boldsymbol{\tau})$.

The administrative costs are thus only a function of the tax structure, and not of the level of taxation. This assumption is crucial in order to simplify the analysis. It implies that the cost of increasing tax revenue is only due to increasing distortionary costs, except in the rare cases where such changes produce a shift in the optimal tax-tariff structure and thus change the administrative costs. However, from an empirical point of view the assumption is problematic. Increasing the level of taxation will strengthen households' incentive to cheat and thus the justification of the government to use resources to discourage such cheating. In the concluding section, where we discuss the policy implications of our theoretical results, we therefore consider how taking tax evasion into account would modify our conclusions. However, as the standard theory of optimal taxation also abstracts from tax evasion, the assumption is consistent with this theory.

A2: The costs of tax administration, $B(\boldsymbol{\Xi}, d)$, decrease in relative importance with increasing levels of economic development, $d$.

Economic development improves the comparative advantage of information processing such as tax administration. It also increases the relative size of the public sector, thus increasing the marginal distortionary costs of raising government revenue. For both reasons, the administrative costs of taxation decrease in importance relative to the distortionary costs.

A3: The costs of tax administration, $B(\boldsymbol{\Xi}, d)$, increase with the number of transactions subject to taxation and with the number of different tax rates employed according to the tax-tariff structure, $\boldsymbol{\Xi}^{3}$

The administrative costs associated with collecting revenue using tariffs will in general be smaller than when using domestic taxes because the number of collection points is smaller and, as a consequence, the size of each transaction larger. Furthermore, for a given set of transactions subjected to taxation, different tax rates complicate compliance by firms and also tax collection and enforcement by the government. A commodity tax structure or tariff tax structure at uniform rates will therefore in general be associated with smaller administrative costs than a corresponding structure with different rates.

\section{The model}

Adopting a simplified version of the theoretical framework of Dasgupta and Stiglitz (1974) and Heady and Mitra $(1982,1987)^{4}$, we consider the problem of optimal taxation in a small open

\footnotetext{
${ }^{3}$ A2 and A3 are key assumptions in the analysis of Kimbrough and Gardner (1992), who use a public finance model to explain the change in the relative role of tariffs and other taxes in the history of the US (see also Section 5).

4 Dasgupta and Stiglitz (1974) and Heady and Mitra (1982, 1987) consider more than one primary factor. The reason why we adopt the rather restrictive assumption of only one primary factor is to be able to interpret our results drawing on the insight provided by the standard theory of optimal taxation based on fixed producer prices. Expanding the model to represent more than one primary factor would make producer prices endogenous, and the trade-off between differential factor taxes (creating production inefficiency) and administrative costs would then also have to be
} 
economy with one representative household, three perfectly competitive production sectors, and a government. In the economy there is one primary factor, indexed 0 , and three tradable commodities, indexed (1,2,3). The government imposes border taxes, $\mathbf{t}^{\mathrm{W}} \equiv\left(t_{1}^{W}, t_{2}^{W}, t_{3}^{W}\right)$, and household taxes $\mathbf{t}=\left(t_{0}, t_{1}, t_{2}, t_{3}\right)$. World market prices are $\mathbf{p}^{W} \equiv\left(p_{1}^{W}, p_{2}^{W}, p_{3}^{W}\right)$, producer prices are $\mathbf{p} \equiv\left(p_{0}, p_{1}, p_{2}, p_{3}\right)=\left(p_{0}, p_{1}^{W}+t_{1}^{W}, p_{2}^{W}+t_{2}^{W}, p_{3}^{W}+t_{3}^{W}\right)$, and household prices are $\mathbf{q} \equiv\left(q_{0}, q_{1}, q_{2}, q_{3}\right)=$ $\left(p_{0}+t_{0}, p_{1}+t_{1}, p_{2}+t_{2}, p_{3}+t_{3}\right)$.

The economy has the potential to produce any of the three commodities using only the primary factor as input. The production structure exhibits constant returns to scale. Hence, the economy will specialise in the production of one commodity, which thus becomes the export good, while the two other commodities become the import goods. The output of the export sector is $y_{1}$, and the use of the primary factor for its production is $y_{0}{ }^{5}$ The production function for the export sector is

$$
y_{1}=-a_{0} y_{0}
$$

and, by the zero profit condition, the producer price of the primary factor is

$$
p_{0}=a_{0} p_{1}
$$

The household's endowment of the primary factor is $\omega_{0}$, and its net demand vector is $\left(x_{0}, x_{1}, x_{2}, x_{3}\right)$. The household's untaxed consumption of the primary factor, representing the use of resources in the informal sector of the economy, is thus $\omega_{0}+x_{0}{ }^{6}$ The preferences of the household are represented by the expenditure function, $E(\mathbf{q}, u)$, defined over household prices, $\mathbf{q}$, and utility, $u$. The household's net demands are given $b^{7}$

$$
x_{i}=E_{i}(\mathbf{q}, u) \quad i=0,1,2,3
$$

Foreign trade is $\left(y_{1}^{W}, y_{2}^{W}, y_{3}^{W}\right)$. The balance of trade constraint is thus

$$
\sum_{i \in(1,2,3)} p_{i}^{W} y_{i}^{W}=0
$$

considered. We have analysed this trade-off elsewhere (see Munk 1980 and 1998), and incorporating it here would complicate the exposition without contributing much to achieving the objectives of the paper (see Section 1).

${ }^{5}$ The sign conventions are: $y_{0}<0$ and $y_{1}>0 ; x_{0}<0$ and $x_{\mathrm{i}}>0(\mathrm{i}=1,2,3) ; y_{1}{ }^{\mathrm{w}}<0$ and $y_{i}^{W}>0,(i=2,3)$. Thus for the primary factor tax and the export tax, respectively, to generate a positive tax revenue, the tax rates must be negative.

${ }^{6}$ We disregard the possibility of intermediate consumption, in particular that the goods produced in the informal sector are used as input in the formal sector.

${ }^{7}$ We utilize the derivative notation writing $E_{i} \equiv \frac{\partial E}{\partial q_{i}}, i=0,1,2,3$, and $E_{i j} \equiv \frac{\partial^{2} E}{\partial q_{i} \partial q_{j}}, i, j=0,1,2,3$. 
The government's choice of tax- and tariff rates is subject to tax-tariff restrictions. We express restrictions on domestic tax rates as ${ }^{8}$

$$
T_{i} \equiv\left(t_{i}+p_{i}\right) / p_{i}=\bar{T}_{i}, \quad i=0,1,2,3
$$

and on tariffs as

$$
T_{i}^{W} \equiv\left(t_{i}^{w}+p_{i}^{w}\right) / p_{i}^{w}=\bar{T}_{i}^{W}, \quad i=1,2,3
$$

Since the administrative costs for all tax-tariff systems belonging to a given tax-tariff structure $\boldsymbol{\Xi}^{j}$ are $B\left(\boldsymbol{\Xi}^{j}, d\right)$, and the government's resource requirement for other expenditures than tax administration is assumed exogenously given, the government's total resource requirement is

$$
x_{i}^{G}=x_{i}^{G}\left(\boldsymbol{\Xi}^{j}, d\right) \quad i=0,1,2,3
$$

We assume that $x_{i}^{G}\left(\boldsymbol{\Xi}^{j}, d\right)$ is not influenced by changes in consumer prices. ${ }^{9}$

For a tax-tariff system, $\left(\mathbf{t}, \mathbf{t}^{W}\right) \in \mathbf{\Xi}^{j}$, the government's budget constraint is

$$
\sum_{\mathrm{i}=0,1,2,3} t_{i} x_{i}+\sum_{\mathrm{i}=1,2,3)} t_{i}^{W} x_{i}^{W}-\sum_{\mathrm{i}=0,1,2,3} p_{i} x_{i}^{G}\left(\mathbf{\Xi}^{j}, d\right)=0
$$

Material balance requires

$$
\begin{array}{ll}
y_{0}=x_{0}+x_{0}^{G} & \\
y_{1}+y_{1}^{W}=x_{1}+x_{1}^{G} & \\
y_{i}^{W}=x_{i}+x_{i}^{G} & i=2,3
\end{array}
$$

Substituting by (1) in (8), and by (3) and (5) in (7), (8) and (9), and subsequently substituting for $y_{0}$ by (7) in (8), yields

$$
\begin{aligned}
& y_{1}^{W}=a_{0}\left[E_{0}(\mathbf{q}, u)+x_{0}^{G}\left(\mathbf{\Xi}^{j}, d\right)\right]+E_{1}(\mathbf{q}, u)+x_{1}^{G}\left(\mathbf{\Xi}^{j}, d\right) \\
& y_{i}^{W}=E_{i}(\mathbf{q}, u)+x_{i}^{G}\left(\boldsymbol{\Xi}^{j}, d\right) \\
& i=2,3
\end{aligned}
$$

World market prices, $\mathbf{p}^{W} \equiv\left(p_{1}^{W}, p_{2}^{W}, p_{3}^{W}\right)$, are exogenously determined, and the producer price of the primary factor, $p_{0}$, is fixed as a matter normalisation without loss of generality.

\footnotetext{
${ }^{8}$ For example, $\bar{T}_{0}=1$ indicates that it is not possible to tax the primary factor; $\left\{\bar{T}_{\mathrm{i}}=1, i=0,1,2,3\right\}$ indicates that domestic commodity taxes are not feasible; and $\left\{\bar{T}_{\mathrm{i}}^{w}=1, i=1,2,3\right\}$ that border taxes cannot be used.

${ }^{9}$ This is not an entirely innocent assumption, as a renormalisation which makes one commodity rather than another untaxed may have implications for the costs of tax administration.
} 
Finally, we substitute (10) and (11) into the balance of trade constraint, (4), and into the government's budget constraint, (6). Adopting an approach similar to that used in Dixit and Munk (1977), ${ }^{10}$ the conditions for a tax system, $\left(\mathbf{t}, \mathbf{t}^{W}\right) \in \mathbf{\Xi}^{j}$, to be feasible may then be expressed as

$$
\begin{aligned}
& \mathrm{E}(\mathbf{q}, u) \leq 0 \\
& p_{1}^{\mathrm{W}}\left[a_{0}\left[E_{0}(\mathbf{q}, u)+x_{0}^{G}\left(\boldsymbol{\Xi}^{j}, d\right)\right]+E_{1}(\mathbf{q}, u)+x_{1}^{G}\left(\boldsymbol{\Xi}^{j}, d\right)\right]+\sum_{i \in 2,3} p_{\mathrm{i}}^{\mathrm{W}}\left[E_{i}(\mathbf{q}, u)+x_{i}^{G}\left(\boldsymbol{\Xi}^{j}, d\right)\right] \geq 0 \\
& \sum_{\mathrm{i}=0,1,2,3} t_{i} E_{\mathrm{i}}(\mathbf{q}, u)+t_{1}^{\mathrm{W}}\left[a_{0}\left(E_{0}(\mathbf{q}, u)+x_{0}^{G}\left(\mathbf{\Xi}^{j}, d\right)\right)+E_{1}(\mathbf{q}, u)+x_{1}^{G}\left(\mathbf{\Xi}^{j}, d\right)\right] \\
& +\sum_{i=2,3} t_{\mathrm{i}}^{\mathrm{W}}\left[E_{i}(\mathbf{q}, u)+x_{i}^{G}\left(\mathbf{\Xi}^{j}, d\right)\right]-p_{0} x_{0}^{G}\left(\mathbf{\Xi}^{j}, d\right)-\sum_{i=1,2,3} p_{i} x_{i}^{G}\left(\mathbf{\Xi}^{j}, d\right) \geq 0
\end{aligned}
$$

where $p_{\mathrm{i}}=p_{\mathrm{i}}^{W}+t_{\mathrm{i}}^{W},(\mathrm{i}=1,2,3)$ and $\mathbf{q} \equiv\left(q_{0}, q_{1}, q_{2}, q_{3}\right)=\left(p_{0}+t_{0}, p_{1}+t_{1}, p_{2}+t_{2}, p_{3}+t_{3}\right)$.

By Walras' law, an equilibrium solution can be found disregarding either (13) or (14) and the condition for equilibrium can be expressed by (12) and (13). Without loss of generality, under $\boldsymbol{\Xi}^{2}$ and $\boldsymbol{\Xi}^{3}$, we can then assume that exports are untaxed, and, in addition, under $\boldsymbol{\Xi}^{1}$, that the domestic consumption of the export good is untaxed. ${ }^{11}$

The government maximises social welfare, $u$, subject to the general equilibrium conditions as expressed by (12) and (14). The maximisation takes place in a two-step procedure: First, the government calculates the optimal tax system for each tax structure. Then, based on the results of the first step, it chooses the optimal tax structure, $\mathbf{\Xi}^{*}$, i.e. the tax structure which allows the highest level of social welfare to be attained, and concomitantly the overall optimal tax system, $\left(\mathbf{t}^{*}, \mathbf{t}^{W^{*}}\right)$. Administrative costs are thus exogenous to the choice of tax system for a given tax-tariff structure, but endogenous to the government's overall choice of tax system. The optimal tax structure may therefore change in response to changes in technology, administrative infrastructure and world market prices.

\footnotetext{
${ }^{10}$ The first equation (12) assures that the value of compensated demand is consistent with the household's lump-sum income, the second equation (13) that international trade is balanced, and the third (14) that the government's expenditures are financed by the tax revenue. The conditions for utility maximisation, profit maximisation and material balance are represented by these three equations (see also Diamond and McFadden 1974).

${ }^{11}$ Substituting by $q_{0}=a_{0} T_{0} T_{1}^{W} p_{1}^{W}$ and $q_{i}=T_{i} T_{i}^{W} p_{i}^{W},(i=1,2,3),(12)$ and (13) may be rewritten

$$
\begin{aligned}
& E\left(a_{0} T_{0} T_{1}^{W} p_{1}^{W},\left\{T_{i} T_{i}^{W} p_{i}^{W}, i \in(1,2,3)\right\}, u\right)= \\
& p_{1}^{W}\left[a_{0}\left[E_{0}\left(a_{0} T_{0} T_{1}^{W} p_{1}^{W},\left\{T_{i} T_{i}^{W} p_{i}^{W}, i \in(1,2,3)\right\}, u\right)+x_{0}^{G}\left(\Xi^{j}\right)\right]+E_{1}\left(a_{0} T_{0} T_{1}^{W} p_{1}^{W},\left\{T_{i} T_{i}^{W} p_{i}^{W}, i \in(1,2,3)\right\}, u\right)+x_{1}^{G}\left(\Xi^{j}\right)\right] \\
& +\sum_{\mathrm{i}=2,3} p_{i}^{W}\left[E_{i}\left(a_{0} T T_{1}^{W} p_{1}^{W},\left\{T_{i} T_{i}^{W} p_{i}^{W}, i \in(1,2,3)\right\}, u\right)+x_{i}^{G}\left(\Xi^{j}\right)\right]=0
\end{aligned}
$$
}

Multiplying $T_{i}, \mathrm{i}=0,1,2,3$ by the same constant and similarly multiplying $T_{1}^{W}, \mathrm{i}=1,2,3$ by the same constant will not change demands and will thus leave the equilibrium conditions unaffected. 


\section{Characterisation of the optimal tax-tariff system for different tax structures}

\section{No restrictions}

We first characterise the optimal tax-tariff system under the unconstrained tax-tariff structure, $\boldsymbol{\Xi}^{1}$, i.e. the situation analysed by Dixit (1985). As a matter of normalisation without loss of generality, we assume that both domestic consumption and exports of commodity 1 are untaxed, i.e. $t_{1}=0$ and $t_{1}^{\mathrm{W}}=0$. Hence, the Lagrangian expression corresponding to the government's optimization problem may be expressed as follows (leaving out arguments of functions for readability):

$$
\mathrm{L}=u+\mu(-E)+\lambda\left(\sum_{\mathrm{i}=0,2,3} t_{i} E_{\mathrm{i}}+\sum_{\mathrm{i}=2,3} t_{\mathrm{i}}^{\mathrm{W}}\left(E_{\mathrm{i}}+x_{i}^{G}\right)-p_{0} x_{0}^{G}-\sum_{\mathrm{i}=1,2,3}\left(p_{i}^{W}+t_{\mathrm{i}}^{\mathrm{W}}\right) x_{i}^{G}\right)
$$

The first order conditions with respect to domestic taxes, $t_{k}$, are

$$
-\mu E_{k}+\lambda\left(\sum_{i=0,2,3} t_{i} E_{i k}+E_{k}+\sum_{\mathrm{i}=2,3} t_{i}^{W} E_{i k}\right)=0
$$

and with respect to tariff rates, $t_{k}^{w}$,

$$
-\mu E_{k}+\lambda\left(\sum_{i=0,2,3} t_{i} E_{i k}+E_{k}+\sum_{i=2,3} t_{i}^{W} E_{i k}\right)=0
$$

If $t_{i}^{w}=0, i=2,3$, and if domestic taxes are set so that (16) is satisfied, then also (17) is satisfied. The optimal solution may thus be achieved using only domestic taxes, as may indeed be deduced directly from the Diamond and Mirrlees production efficiency theorem, interpreting the foreign sector as a production sector.

Compared with the first-best allocation, any tax system implies that the household's (untaxed) use of the primary factor in the informal sector ${ }^{12}$ is encouraged or, in other words, that the household's supply of the primary factor to the market is discouraged. Starting with a proportional tax system in terms of produced goods, it is therefore in general possible to alleviate the discouragement of the supply of the primary factor by differentiating the tax rates for the produced commodities. The optimal tax system may thus be interpreted as representing a trade-off between two objectives:

Objective 1: To maintain the first-best pattern of consumption of the produced commodities.

Objective 2: To discourage the untaxed use of the primary factor in the informal sector ${ }^{13}$.

\footnotetext{
${ }^{12}$ As we have assumed that the output from the informal sector is consumed only in the household sector, the untaxed use of the primary factor is equivalent to "leisure" in standard optimal tax models.

${ }^{13}$ To avoid confusion, it is preferable to use the term "untaxed use of the primary factor" rather than "labour" or "leisure". The implications of assuming "labour" untaxed have not always been clearly appreciated in the literature. Whereas the assumption that the household consumption of labour cannot be taxed is a restriction, the assumption that the supply of labour to the market cannot be taxed is just a normalisation rule, which (in the absence of other tax restrictions) implies no loss in generality. That the optimal tax system involves higher taxes on those commodities
} 
Generally speaking, the optimal tax system (see Corlett and Hague 1953, Harberger 1974) will therefore be characterised by,

1) high tax rates on the commodities which are the most complementary with the untaxed use of the primary factor, and

2) greater departure from proportionality, a) the greater the complementarity with the untaxed use of the primary factor in the informal sector; and b) the more the degree of complementarity differs between commodities being produced or being imported.

With the unconstrained tax-tariff structure, $\boldsymbol{\Xi}^{1}$, household prices can be determined by the choice of domestic taxes irrespective of the level of border taxes. Distorting producer prices by using border taxes does therefore not contribute to either of these two objectives. This provides an intuitive explanation of why border taxes are not relevant to the solution of the government's maximization problem. The optimal tax system associated with $\Xi^{1}$ is subject to fewer constraints than the other tax structures. Consequently, from a purely allocative point of view, i.e. disregarding administrative costs, $\boldsymbol{\Xi}^{1}$ is clearly the optimal tax structure. However, it requires monitoring of domestic market transactions for each commodity separately. The administrative costs associated with $\boldsymbol{\Xi}^{1}$ are therefore likely to be significantly larger than for the other tax structures, in particular in countries with a weak administrative infrastructure. Thus, $\boldsymbol{\Xi}^{1}$ may not be the optimal tax structure when both administrative and distortionary costs are taken into account.

\section{Only border taxes and VAT}

We now characterise the optimal tax-tariff system when the government's revenue requirement can be financed only by tariffs and by a tax on the market supply of the primary factor (corresponding to a proportional income tax or to a VAT), i.e. when the tax-tariff system belongs to $\boldsymbol{\Xi}^{2}$ where $\bar{T}_{\mathrm{i}}=1, i=1,2,3^{14}$. This problem is similar to that analysed by Heady and Mitra (1982).

As in the previous case of unconstrained taxation, we assume as a matter of normalisation without loss of generality that the export of commodity 1 is untaxed, i.e. $t_{1}^{\mathrm{W}}=0$. The first order conditions for $\left(\mathbf{t}, \mathbf{t}^{W}\right)$ to be an optimal solution to the government's maximisation problem under $\boldsymbol{\Xi}^{2}$, are

\footnotetext{
which are complementary with the household consumption of "leisure" is thus not just a consequence of the normalisation rule adopted (as claimed by several authors, for example Myles 1995, pp 123-124), but due to the fact that a household's own consumption of its primary factor endowment cannot be taxed.

${ }^{14}$ Notice that within the model framework, a tax on the market supply of the primary factor is equivalent to a uniform tax on the final consumption of the commodities produced in the formal sector, i.e. a VAT.
} 


$$
\begin{aligned}
& -\mu E_{0}+\lambda\left(t_{0} E_{00}+E_{0}+\sum_{i \in(2,3)} t_{i}^{W} E_{i 0}\right)=0 \\
& -\mu E_{j}+\lambda\left(t_{0} E_{0 j}+E_{j}+\sum_{i \in(2,3)} t_{i}^{W} E_{i j}\right)=0 \quad \mathrm{j}=2,3
\end{aligned}
$$

Although it is feasible for the government to finance its resource requirements only by domestic taxes and thus maintain production efficiency, this is not the optimal solution. The government can increase welfare by using tariffs to discourage the untaxed use of the primary factor in the informal sector. The optimal tariff structure will thus be determined as a compromise between the same two objectives as in the previous case. As the domestic taxes under $\boldsymbol{\Xi}^{2}$ cannot be manipulated to discourage the use of the primary factor in the formal sector, tariffs are instead used to achieve this objective. Therefore, in countries with a relatively large informal sector, and where there are relatively large differences in the complementarity of different commodities with the use of the primary factor in the informal sector, the benefits derived from using tariffs are relatively more important than in countries where this is not the case. However, this potentially involves a higher distortionary cost than under $\boldsymbol{\Xi}^{1}$, because production decisions may also be distorted. With the imposition of the optimal tariffs, production will either take place in the same sector as under $\boldsymbol{\Xi}^{1}$, or it will switch to another sector. In the first case, consumption will remain unchanged, as the same consumer prices will be sustained by tariffs instead of by domestic taxes. However, in the second case, there will be a loss of allocative efficiency.

The use of tariffs involves monitoring far fewer market transactions than the use of domestic consumer taxes. The administrative costs associated with the tax-tariff structure $\mathbf{\Xi}^{2}$ are therefore smaller than those associated with the unconstrained tax-tariff structure, $\boldsymbol{\Xi}^{1}$. However, if the economy specialises in the production of different goods under the two different tax structures, then choosing between $\boldsymbol{\Xi}^{1}$ and $\boldsymbol{\Xi}^{2}$ involves a trade-off between administrative costs and allocative efficiency. In this case, which tax structure is the optimal cannot be determined a priori on theoretical grounds.

\section{Only tariffs}

We now consider the optimal solution when the government's revenue requirement has to be financed only by tariffs, i.e. under the tax structure $\Xi^{3}$ with $\bar{T}_{\mathrm{i}}=1, i=0,1,2,3 .{ }^{15}$ As the household by the assumption of a linear production technology receives no profit income, a proportional tariff structure

$$
T_{i}^{W} \equiv\left(t_{i}^{w}+p_{i}^{w}\right) / p_{i}^{w}=T^{W}, \quad i=1,2,3
$$

generates no revenue. A tariff structure will therefore in order to generate a revenue necessarily have to encourage the consumption of the export good. With the tariff structure, $\mathbf{\Xi}^{3}$, both the non-

\footnotetext{
${ }^{15}$ This corresponds to the situation analysed for example by Hatta and Ogawa (2003). However, they base their analysis on more general assumptions about the production structure, which complicates the interpretation of results.
} 
market use of the primary factor and the domestic consumption of the export good $^{16}$ will therefore be encouraged compared with the first-best allocation. The optimal tariff system may thus be interpreted as a compromise between the following three objectives:

Objective 1: To maintain the first-best pattern of consumption of the import goods.

Objective 2: To discourage the untaxed consumption of the primary factors.

Objective 3: To discourage the untaxed consumption of the export good.

In other words, in addition to the two objectives considered in the previous cases, also Objective 3 needs to be taken into account.

Assuming, as a matter of normalisation without loss of generality, that exports are untaxed, we may derive tax formulae which clearly bring out these trade-offs. The first order conditions for an optimal tax-tariff system now become

$$
-\mu E_{j}+\lambda\left(E_{j}+\sum_{i=2,3} t_{i}^{W} E_{i j}^{h}\right)=0 \quad \mathrm{j}=2,3
$$

Solving for the optimal tariffs using the symmetry of the Slutsky matrix, we have

$$
\begin{aligned}
& t_{2}^{W}=\theta \frac{\left(-E_{33} E_{2}+E_{23} E_{3}\right)}{D} \\
& t_{3}^{W}=\theta \frac{\left(-E_{22} E_{3}+E_{32} E_{3}\right)}{D}
\end{aligned}
$$

where $D=E_{22} E_{33}-E_{32} E_{23}$, and $\theta=\frac{\lambda-\mu}{\lambda}$

Defining compensated price elasticities as $\varepsilon_{i j} \equiv E_{i j} / \frac{x_{i}}{q_{j}},(i, j=0,1,2,3),(21)$ and (22) may be transformed into

$$
\begin{aligned}
& \frac{t_{2}^{W}}{q_{2}}=\theta \frac{\left(\varepsilon_{23}-\varepsilon_{33}\right)}{\varepsilon_{22} \varepsilon_{33}-\varepsilon_{32} \varepsilon_{23}} \\
& \frac{t_{3}^{W}}{q_{3}}=\theta \frac{\left(\varepsilon_{32}-\varepsilon_{22}\right)}{\varepsilon_{22} \varepsilon_{33}-\varepsilon_{32} \varepsilon_{23}}
\end{aligned}
$$

By homogeneity of degree zero of the compensated demand functions, $E_{i}(\mathbf{q}, u),(i=0,1,2,3)$, we have that $\sum_{j=0,1,2,3} \varepsilon_{i j}=0,(i=0,1,2,3)$, and since $\varepsilon_{i j}=s_{j} \sigma_{i j}$ where $\sigma_{i j}$ is the Allen elasticity of substitution, and $s_{j}$ the share of the consumption of $\mathrm{j}$ in full income, the optimal tariff system may be expressed as (see Munk and Rasmussen 2005)

\footnotetext{
16 As pointed out by Hatta and Ogawa (2003), there is an analogy to the rationale to tax commodities at a higher rate the more they are complementary to the untaxed use of the primary factor.
} 


$$
\frac{t_{2}^{W} / q_{2}}{t_{3}^{W} / q_{3}}=\frac{\left(s_{2}+s_{3}\right) \sigma_{23}+s_{1} \sigma_{31}+s_{0} \sigma_{30}}{\left(s_{2}+s_{3}\right) \sigma_{23}+s_{1} \sigma_{21}+s_{0} \sigma_{20}}
$$

The optimal tariff system reflects the objectives of discouraging both the untaxed consumption of the primary factor and the untaxed domestic consumption of the export good. Which commodity will be taxed at the highest rate depends entirely on the sign of $\varphi \equiv s_{0}\left(\sigma_{30}-\sigma_{20}\right)+s_{1}\left(\sigma_{31}-\sigma_{21}\right)$ where $s_{0}\left(\sigma_{30}-\sigma_{20}\right)$ is a measure of the importance of Objective 2 and $s_{1}\left(\sigma_{31}-\sigma_{21}\right)$ of Objective 3 . For a given value of $\sigma_{23}$ (which may be taken as a measure of the importance of Objective 1), the difference in the tax rates will be greater, the greater the numerical value of $\varphi$; and for a given value of $\varphi$, the difference will be smaller the greater is $\sigma_{23}$. Objectives 2 and 3 may be conflicting, but if Objective 2 is more important than Objective 3, or if Objective 3 draws the tariff system in the same direction as Objective 2, a relatively large informal sector (as measured by $s_{0}$ ) and a large difference in the complementarity of the imported commodities with the use of the primary factor in the informal sector (as measured by $\sigma_{30}-\sigma_{20}$ ), imply that a country will derive relatively large benefits from a differentiated tariff structure.

Compared with the optimal tax-tariff system obtained under the two previous tax structures, the optimal solution involves increased distortionary costs, because domestic taxes cannot be used to discourage the domestic consumption of the export good and the untaxed consumption of the primary factor. On the other hand, the administrative costs of raising government revenue only by tariffs are likely to be significantly smaller than for the two other tax-tariff structures, because under $\boldsymbol{\Xi}^{3}$ domestic market transactions are not taxed. Therefore, on theoretical grounds alone, it cannot be ruled out that a tax system belonging to $\Xi^{3}$ is the overall optimal tax system.

\section{Only uniform tariff}

Finally, under $\boldsymbol{\Xi}^{4}$, where $\bar{T}_{\mathrm{i}}=1, i=0,1,2,3, T_{1}^{W}=1, T_{i}^{W}=\bar{T}_{i}^{W}, i=2,3$, assuming, as a matter of normalisation without loss of generality, that exports are untaxed, only one tax-tariff system is feasible. This tax-tariff structure implies greater distortionary costs than the other tax-tariff structures and in particular than a differentiated tariff system. However, by the same token, this taxtariff structure is likely to be associated with the smallest administrative costs, since only foreign transactions are taxed, and at the same rate (see assumption A3).

\section{The trade-off between allocative efficiency and administrative costs}

Writing $W\left(\boldsymbol{\Xi}^{j}, d\right)$ as the maximum social welfare at the level of economic development, $d$, associated with the tax-tariff structure $\mathrm{j}$, we have, disregarding administrative costs,

$$
\text { T1: } W\left(\boldsymbol{\Xi}^{1}, d\right) \geq W\left(\boldsymbol{\Xi}^{2}, d\right) \geq W\left(\boldsymbol{\Xi}^{3}, d\right) \geq W\left(\boldsymbol{\Xi}^{4}, d\right)
$$


since $W\left(\boldsymbol{\Xi}^{j}, d\right)$ is by general rules of optimisation non-decreasing in the number of tax-tariff instruments available to the government.

Since by assumption $\boldsymbol{A 3}$ the costs of tax administration are increasing with the differentiation of the tax-tariff structure and with the number of transactions which are subject to taxation, the tax-tariff structures may be ranked in terms of administrative costs as follows

$$
\text { T2: } B\left(\boldsymbol{\Xi}^{1}, d\right) \geq B\left(\boldsymbol{\Xi}^{2}, d\right) \geq B\left(\boldsymbol{\Xi}^{3}, d\right) \geq B\left(\boldsymbol{\Xi}^{4}, d\right)
$$

This ranking is thus the opposite of the ranking based only on allocative considerations, $\boldsymbol{T} \boldsymbol{1}$. There is, therefore, a trade-off between allocative efficiency and administrative costs, which does not allow the optimal tax-tariff structure to be identified without empirical evidence on both the structure of the economy and the costs of tax administration in the country in question.

\section{The evolution of the optimal tax-tariff structure and desirable directions of tax-tariff reform}

In this section, we consider the implications of the theoretical analysis for the evolution of the optimal tax structure over time, and for desirable directions of tax-tariff reform. Assuming that the political system behaves as if the government maximises the utility of a representative household, the analysis may be interpreted as a positive theory of taxation in an open economy. Given this interpretation, the theory provides an explanation of the evolution of the tax-tariff system consistent with that of Kimbrough and Gardner (1992). On the basis of assumptions similar to assumptions $\boldsymbol{A 2}-\boldsymbol{A 3}$ and taking US tariff history as an example, Kimbrough and Gardner (1992) explain why the importance of tariff revenue has diminished over time. But, as they assume a fixed factor supply and only one import good, their analysis does not capture the importance of the interaction of the consumption of the import goods neither with the use of the primary factor in the informal sector nor with the consumption of the export good.

The main objective of this paper is, however, to identify desirable directions of tax-tariff reform. In this context, the relative economic importance of the informal sector in the economy plays an important role. In order to bring this out, we make one further assumption, which is amply supported by empirical evidence (see for example Schneider and Enste 2002):

A4: The size of the informal sector measured by the share in full income of the consumption of the primary factor in the informal sector, $s_{0}$, decreases with increasing levels of economic development.

This assumption in combination with assumptions $\boldsymbol{A 1 - A 3}$ implies that the benefits which can be derived from the use of tariffs will decrease with economic development. As illustrated in Table 1, the optimal tax-tariff structure will evolve through three transitional phases, each characterised by different directions of a desirable tax-tariff reform. The first transition from $\boldsymbol{\Xi}^{4}$ to $\boldsymbol{\Xi}^{3}$ corresponds to the situation where the administrative infrastructure has improved to the point where the differentiation of the tariff rates has become preferable to a uniform tax structure. The second 
transition from $\boldsymbol{\Xi}^{3}$ to $\boldsymbol{\Xi}^{2}$ corresponds to the situation where it has become desirable to finance government expenditures by domestic taxes at a uniform rate, maintaining border taxes only to discourage the use of resources in the informal sector. Finally, the third transition from $\boldsymbol{\Xi}^{2}$ to $\boldsymbol{\Xi}^{1}$ involves the adoption of free trade, as it becomes desirable to differentiate domestic tax rates to balance the objective of maintaining the pattern of first-best consumption of produced commodities with the objective of discouraging the use of resources in the informal sector.

Table 1: The level of development and the optimal tax-tariff system

\begin{tabular}{|c|c|c|}
\hline $\begin{array}{l}\text { Optimal tax- } \\
\text { tariff structure }\end{array}$ & $\begin{array}{c}\text { Level of } \\
\text { economic } \\
\text { development }\end{array}$ & The purpose served by the optimal tariff structure \\
\hline $\begin{array}{l}\text { Uniform tariff } \\
\text { rate: } \Xi^{4}\end{array}$ & Low & $\begin{array}{l}\text { The uniform tariff serves no other purpose than to finance the } \\
\text { government's resource requirement. }\end{array}$ \\
\hline Border taxes: $\mathbf{\Xi}^{3}$ & $\begin{array}{l}\text { Lower- } \\
\text { middle }\end{array}$ & $\begin{array}{l}\text { The optimal tariff structure 1) reduces the use of resources in } \\
\text { the informal sector, and 2) reduces the consumption of the } \\
\text { export commodity }\end{array}$ \\
\hline $\begin{array}{l}\text { Border taxes } \\
+ \text { VAT: } \boldsymbol{\Xi}^{2}\end{array}$ & $\begin{array}{l}\text { Upper- } \\
\text { middle }\end{array}$ & $\begin{array}{l}\text { The optimal tariff structure reduces the use of resources in the } \\
\text { informal sector }\end{array}$ \\
\hline $\begin{array}{l}\text { Differentiated } \\
\text { domestic taxes: } \\
\boldsymbol{\Xi}^{1}\end{array}$ & High & $\begin{array}{l}\text { Tariffs serve no purpose. } \\
\text { The reduction of the untaxed use of primary factors is achieved } \\
\text { by differentiating domestic commodity taxes. }\end{array}$ \\
\hline
\end{tabular}

Thus, important implications of our analysis are, first, that although the process of economic development is continuous, the development of the optimal tax system is not, and, second, that investments in the administrative infrastructure in a developing country will result in liberalisation of trade at an earlier stage than would otherwise be the case. These implications have important consequences for the advice and technical assistance to be given to developing countries. Due to the associated fixed costs, the tax structure should change only after the trade-off between administrative costs and distortionary costs has changed sufficiently to justify the transition. However, when a change the tax structure has been decided, the tax system will need to undergo a substantial transformation, because all tax rates - not only those which have previously been constrained - will need to change as the purpose which the tax system has to serve has changed (see Table 1). Consider, for example, the situation of a government in a lower-middle income country considering a tax-tariff reform which involves replacing $\boldsymbol{\Xi}^{3}$ with $\boldsymbol{\Xi}^{2}$. In this situation the government must assess the implications of such a tax-tariff reform, not only in terms of the administrative and distortionary costs of implementing a VAT system, but also in terms of the adjustment of the border taxes to reflect the reduced need for tariffs to generate government revenue. Furthermore, it must take into account that tariffs no longer should be used to discourage 
the consumption of the export commodity, but only the use of resources in the informal sector. This means that during these transitional phases, there will be a particularly strong need for advice on how to change the tax system in response to factors exogenous to the model.

The IMF and the World Bank have advocated that developing countries, in fact even the least developed countries, should abolish border taxes in favour of broad-based taxes like VAT. These recommendations have been supported by Keen and Ligthart (2002), but have been strongly criticised by Emran and Stiglitz (2005). They point out that Keen and Ligthart's analytical results critically depend on their (implicit) assumption that there is no informal sector in the economy, where in fact developing countries in general have relatively large informal sectors. As the present analysis illustrates, taking administrative costs into account may justify diversions from free trade and explain why many developing countries have resisted the pressure to eliminate border taxes. The results of our analysis are largely consistent with Emran and Stiglitz's criticism. First, the least developed countries may not benefit from the introduction of domestic taxes, as the allocational benefits may be limited and outweighed by increasing administrative costs. Second, even when it is in the interest of a developing or transition country to adopt a VAT regime, it may not be in its interest to give up the use of border taxes entirely. It may still be desirable to levy tariffs in order indirectly to tax the use of resources in the informal sector, alleviating the distortion implied by the partial coverage of the VAT. A recent paper by Baunsgaard and Keen (2005) implicitly provides support to these conclusions. Based on convincing empirical evidence, the paper finds the replacement of border taxes with a VAT has resulted in increased government revenue for high income countries, but the opposite has been the case for low income countries. They consider the revenue effect itself as troubling. However, it seems that basically the reason for concern should be that such tax reforms may have increased the marginal costs of raising government revenue, and thus resulted in a decrease in social welfare. This is not the least disconcerting considering the massive pressure these countries have been subjected to by the international community to undertake this policy change. ${ }^{17}$

However, when attempting to draw policy conclusions, it is important to take into account that the analysis has been based on highly simplifying assumptions. In particular, the effects of the choice of tax structure on the possibilities for income redistribution, tax evasion and rent seeking have been disregarded. These effects are important to take into account when providing advice on tax-tariff reform. The question is therefore if basing the analysis on more realistic assumptions will modify the conclusions reached so far. First, taking into account distributional considerations seems to further reinforce the rationale for using border taxes in developing countreis, as border taxes make it possible to achieve distributional objectives that cannot be achieved by a VAT at a standard rate. When industries, such as agriculture, coal, steel, and textile, come under pressure in the process of economic development, or because of the opening up of domestic markets to international competition, this often causes severe income distributional problems. In general, highly developed countries are well equipped to deal with these problems. Due to their higher level of development, they are able to establish and enforce tax and transfer systems which are typically far more efficient in achieving distributional objectives than border taxes. However, for less developed countries, not being able to use border taxes may imply that they are unable to achieve revenue and distributional objectives, which they could have achieved using border taxes.

\footnotetext{
${ }^{17}$ Our analysis has thus also important implications for the discussion of the fairness of symmetric commitments in international trade negotiations. Even if free trade enhances social welfare for highly developed countries, obliging countries in transition, and in particular the least developed countries, to adopt free trade may result in a significant loss of social welfare for these countries.
} 
Another important consideration regarding the choice of tax structure is, as mentioned in Section 2, the scope it creates for tax evasion. The effect of tax evasion on the administrative costs and the distortionary effect of taxation have been considered in the tradition started by Allingham and Sandmo (1972), and have been summarised in Andreoni et al. (1998). For example, taking tax evasion into account, the scope for substitution between the consumption of different commodities and the use of resources in the informal sector, $\sigma_{i 0}$, would increase, potentially creating a greater allocative benefit of a differentiated tax-tariff structure. As high administrative costs prevent the implementation of a differentiated domestic tax system, taking tax evasion into account thus seems to provide an additional reason for developing countries to use tariffs to raise revenue. However, a full assessment of the implication for the choice of tax-tariff structure of taking tax evasion into account goes beyond the scope of this paper.

A final concern is the importance of political economy considerations. Rent seeking behaviour and corruption are major problems in many developing countries. This, however, does not automatically imply a preference for domestic taxes over border taxes. First, as is the case for domestic taxes, tariffs can be levied at the same rate to limit the scope for rent seeking, and, as pointed out by Bird (2005), the lobbying pressure for exemptions from VAT in developing countries is no less acute than for differentiated tariff rates. Second, even if border taxes are more susceptible to distortion due to rent seeking and corruption than domestic taxes, the difference may not be sufficiently important to justify significant modifications to the recommendations based on public economic considerations. Supporters of the so-called 'Washington consensus', seem to believe that the type of tax system which is desirable for developed countries is also the best for developing countries. It is therefore not surprising if they have interpreted the widespread use of tariffs in developing countries as a result of rent seeking and corruption. However, as our analysis suggests, imposing high and differentiated tariff rates may in fact for a poor country with a large informal sector and difficulties in monitoring activities for tax purposes be a rational response to the problem of raising government revenue at minimum economic costs. It is therefore possible that distortions of the resource allocation due to rent seeking activities are smaller than has previously been thought. This is actually the conclusion reached by Gordon and Li (2005). They demonstrate that a political economy model in the tradition of Grossman and Helpman (1994) poorly reconciles many aspects of the data on tax-tariff structures in developing countries compared with their own model which, as the model adopted in this paper, recognises the importance of the informal sector. ${ }^{18}$ Their results suggest that taking political economy considerations into account does not substantially alter the policy conclusions reached within a public economics framework. This does not detract from the importance of political economy approaches in a number of other respects, such as for the understanding of how the differentiation of tax rates for a given tax structure is influenced by powerful social groups and corrupt officials.

\footnotetext{
${ }^{18}$ Gordon and $\mathrm{Li}$ (2005) assume that due to insufficient administrative infrastructure governments in poor countries are not able to tax activities of firms which do not use financial intermediation. Further, they assume that firms differ in their needs to use financial intermediation and that the incentive for firms to opt out of the use of the formal sector in general is greater than in developed countries. Formulated within the framework of our model, this means that the size of the informal sector, $s_{0}$, is large, and that the elasticities of substitution $\sigma_{i 0}$ are also large and of different size for different commodities. As we have seen, given these assumptions the use of differentiated tariff rates is likely to be welfare improving as it allows the use of resources in the informal sector to be taxed indirectly.
} 


\section{Concluding remarks}

In this paper, we have added structure to the standard theory of optimal taxation in order to represent the trade-off between the objectives of limiting distortionary costs and of limiting the administrative costs of taxation. This has resulted in an optimal tax theory which permits the endogenous choice of tax restrictions. Interpreted as a positive theory, it explains why the tax-tariff system evolves through transitional phases characterised by significant changes in tax rates and with the role of tariff revenue as source of government revenue declining over time. The main achievement of the paper is, however, to have established a framework for identifying desirable directions of tax-tariff reform taking administrative costs into consideration. This helps clarify the reasons for, and lends support to, the criticism by Emran and Stiglitz (2005) of the IMF and the World Bank's recommendation to developing countries to adopt VAT to replace border taxes. The analysis also provides a rationale for the international community to give technical assistance to the improvement of the administrative infrastructure in developing countries in order to stimulate trade liberalisation.

The analysis highlights the importance of taking administrative costs into account when providing recommendations on tax-tariff reform and the fact that such recommendations should not be made based on theoretical considerations alone. A priority for future research must therefore be to gather further empirical evidence on the administrative costs of taxation. There is clearly also a need for further theoretical work to improve the micro foundation for understanding of how administrative costs, tax evasion, and rent seeking influence the choices and enforcement of tax structures in developing countries. In this context, the work of Gordon and Li (2005) and the framework established in this paper may prove useful. Furthermore, with improved theoretical insight and better empirical knowledge, the construction of Computable General Equilibrium (CGE) models constitutes a promising avenue for identifying in practice desirable directions of tax-tariff reform, an approach forcefully advocated and already pursued by Anderson (2002) and others. 


\section{References}

Allingham, M. and A. Sandmo (1972), "Income tax evasion: a theoretical analysis", Journal of Public Economics, 1, 323-338.

Andreoni, J., B. Erard, and J. Feinstein (1998), "Tax compliance", Journal of Economic Literature, 96, 818-860.

Anderson, J.E., (2002), "Trade reform diagnostics with many households, quotas and tariffs", Review of International Economics, 10, (2), 215-36.

Baunsgaard, T. and M. Keen (2005), “Tax revenue and (or) trade liberalisation, Working Paper, $I M F$.

Bird, R.M. (2005), "Value added taxes in developing and transitional countries", Working Paper, Andrew Young School of Policy Studies, Georgia State University.

Corlett, W.J. and D.C. Hague (1953), "Complementarity and excess burden of taxation", Review of Economic Studies, 21, 21-30.

Dasgupta, P. and J. E. Stiglitz (1974), "Benefit-cost analysis and trade policies", Journal of Political Economy, 82, 1-33.

Diamond, P.A. and D.L. McFadden (1974), "Some uses of the expenditure function in public finance", Journal of Public Economics, 3, 3-21.

Diewert, W. E., A.H. Turunen-Red, and A.D. Woodland (1989), "Productivity and Paretoimproving changes in taxes and tariffs", Review of Economic Studies, 56, 199-216.

Dixit, A. K. (1985), “Tax policy in open economies," in Handbook of Public Economics, Vol. I, eds. A.J. Auerbach and M. Feldstein (Amsterdam: North-Holland).

Dixit, A.K. and V. Norman (1980), The theory of international trade, Cambridge University Press.

Dixit, A and K. J. Munk (1977), "Welfare effects of tax and price changes. Correction", Journal of Public Economics, 8, 103-107.

Evans, C. (2003), "Studying the studies: An overview of recent research into taxation operating costs, eJournal of Tax Research, 1, 64-92.

Emran, M. S. and J. Stiglitz (2005), "On selective indirect tax reform in developing countries", Journal of Public Economics, 89, 599-623.

Gordon, R. and W. Li (2005), "Puzzling tax structures in developing countries: A comparison of two alternative explanation", NBER Working Paper.

Grossman, G. and E. Helpman (1994), "Protection for sale", American Economic Review, 84, 83350 . 
Harberger, A. C. (1974), “Taxation and welfare”, Chicago University Press.

Hatta, T. (1977), “A recommendation for a better tariff structure”, Econometrica, 45, 1869-69.

Hatta, T. and Y. Ogawa (2003), "A theory of optimal tariffs under a revenue constraint", CSIS Discussion Paper.

Heady, C. and P. Mitra (1982), "Restricted redistributive taxation, shadow prices and trade policy", Journal of Public Economics, 17, 1-22.

Heady, C. and P. Mitra (1987), "Distributional and revenue raising arguments for tariffs", Journal of Development Economics, 26, 77-101.

Keen, M. and J. E. Ligthart (2002), "Coordinating tariff reduction and domestic tax reform", Journal of International Economics, 56, 489-507.

Kimbrough, K.P. and G. W. Gardner (1992), "Tax Regimes, Tariff Revenues, and Government Spending", Economica, 59, 75-92.

Laffont, J. J. (2004), "Management of public utilities in China", Annals of Economics and Finance, 5, 185-210.

Munk, K. J. (1980), "Optimal taxation with some none-taxable commodities", Review of Economic Studies, 47, 755-765.

Munk, K. J. (1998), "Administrative costs and production efficiency", EPRU Working Paper, University of Copenhagen.

Munk, K. J. and B. Rasmussen (2005), "On the determinants of optimal border taxes for a small open economy", Working Paper, University of Aarhus.

Myles, G. D. (1995), Public Economics, Cambridge University Press.

OECD (2004), Tax administration in OECD countries: Comparative Information Series.

Schneider, F. and D. H. Enste (2002), "Shadow economies: Size, causes, and consequences", Journal of Economic Literature, 38, pp 77-114.

Stiglitz, J. E. and P.S. Dasgupta (1971), "Differential taxation, public goods and economic efficiency", Review of Economic Studies, 38, 151-174.

World Bank (1988), World Development Report 1988, Oxford University Press. 